\title{
Enhanced risk of concurrent regional droughts with increased ENSO variability and warming
}

Jitendra Singh ( $\nabla_{\text {jitendra.singh@wsu.edu ) }}$

School of the Environment, Washington State University, Vancouver, WA, USA

Moetasim Ashfaq

Climate Change Science Institute, Oak Ridge National Laboratory, Oak Ridge, TN

https://orcid.org/0000-0003-4106-3027

\section{Christopher Skinner}

Department of Environmental, Earth and Atmospheric Sciences, University of Massachusetts Lowell,

Lowell, MA, USA

Weston Anderson

Columbia University https://orcid.org/0000-0003-3755-9943

Vimal Mishra

Indian Institute of Technology Gandhinagar https://orcid.org/0000-0002-3046-6296

Deepti Singh

Washington State University, Vancouver

\section{Article}

Keywords: Spatially Compound Extremes, Earth System Model, Large Ensemble, Boreal Summer, Compound Droughts

Posted Date: April 1st, 2021

DOl: https://doi.org/10.21203/rs.3.rs-347426/v1

License: (c) (i) This work is licensed under a Creative Commons Attribution 4.0 International License.

Read Full License

Version of Record: A version of this preprint was published at Nature Climate Change on February 3rd, 2022. See the published version at https://doi.org/10.1038/s41558-021-01276-3. 


\section{Enhanced risk of concurrent regional droughts with increased ENSO \\ 2 variability and warming}

Jitendra Singh ${ }^{1 *}$, Moetasim Ashfaq ${ }^{2+}$, Christopher B. Skinner ${ }^{3}$, Weston B. Anderson ${ }^{4}$, Vimal

5 Mishra $^{5,6}$, Deepti Singh ${ }^{1}$

${ }^{1}$ School of the Environment, Washington State University, Vancouver, WA, USA.

${ }^{2}$ Computational Sciences and Engineering Division, Oak Ridge National Laboratory, Oak Ridge, 9 TN, USA.

$10{ }^{3}$ Department of Environmental, Earth and Atmospheric Sciences, University of Massachusetts

11 Lowell, Lowell, MA, USA.

12 International Research Institute for Climate and Society, Columbia University, Palisades, NY, 13 USA.

$14{ }^{5}$ Civil Engineering, Indian Institute of Technology (IIT) Gandhinagar, Gandhinagar, Gujarat, 15 India

$16{ }^{6}$ Earth Sciences, Indian Institute of Technology (IIT) Gandhinagar, Gandhinagar, Gujarat, India

*Corresponding author, Email: jitendra.singh@wsu.edu

Abstract:

Spatially compound extremes pose substantial threats to globally interconnected socialeconomic systems. We use an Earth system model large ensemble to examine the future risk of compound droughts during the boreal summer over ten global regions with highly seasonal climate. Relative to the late- $20^{\text {th }}$ century, the probability, mean extent and severity of compound droughts increase by $\sim 60 \%, \sim 10 \%$ and $\sim 20 \%$ respectively by the late-2 $1^{\text {st }}$ century, with a disproportionate increase in risk across North America and the Amazon. These changes result in a $\sim 9$-fold increase in exposure over agricultural areas and $\sim 5$ to 20 fold increase in population exposure depending on the shared socioeconomic pathway. ENSO is the predominant large-scale driver of compound droughts with $68 \%$ of historical events occurring during EI Niño or La Niña conditions. ENSO teleconnections remain

\footnotetext{
+ This manuscript has been co-authored by employees of Oak Ridge National Laboratory, managed by UT Battelle, LLC, under contract DE-AC05-00OR22725 with the U.S. Department of Energy. The publisher, by accepting the article for publication, acknowledges that the United States Government retains a non-exclusive, paid-up, irrevocable, world-wide license to publish or reproduce the published form of this manuscript, or allow others to do so, for United States Government purposes. The Department of Energy will provide public access to these results of federally sponsored research in accordance with the DOE Public Access Plan (http://energy.gov/downloads/doe-public-access-plan)
} 
stationary in the future though an $\sim 22 \%$ increase in ENSO extremes combined with projected warming, drive the elevated risk of compound droughts.

Spatially and/or temporally compounding Earth system extremes can lead to cascading impacts on global socio-economic systems ${ }^{1-6}$. Several recent studies have examined temporally compounding events resulting from different combinations of climatic hazards occurring in the same location at the same time, such as hot and dry conditions ${ }^{7,8}$ or heavy precipitation and extreme winds ${ }^{9}$. The simultaneous occurrence of extremes across multiple regions, referred to as spatially compound extremes, have received relatively limited attention. Spatially compound extremes have the potential to accumulate hazard impacts in distant locations and pose amplifying pressures on a network of interconnected socioeconomic systems ${ }^{1,10-15}$. For example, severe droughts that concurrently occurred across Asia, Brazil, and Africa during 1876 to 1878 led to synchronous crop failures, followed by famines that killed more than 50 million people in those regions ${ }^{16}$. The complex and interconnected nature of the current global food network makes agricultural shocks, even over a few individual regions, capable of having ripple effects on global food prices and food security, particularly in socioeconomically vulnerable regions ${ }^{11,17}$. Compound extremes can also influence global economies through their impacts on international agribusiness and reinsurance industries $7,18,19$. Therefore, understanding the drivers of simultaneous extremes across regions and the exposure of human systems to such extremes can inform assessments of the climate risks to interconnected systems and planning for their societal impacts.

Recent studies have examined the risk of crop failures from compound extremes and highlighted various physical drivers and mechanisms. The risk of multiple-breadbasket failures is elevated during the simultaneous physical hazards imposed by the large-scale natural climate variability modes such as El Niño-Southern Oscillation (ENSO), Indian Ocean Dipole, and Atlantic Niño ${ }^{12,13,20}$. ENSO is one of the predominant drivers of hydroclimate variability across tropical regions, as El Niño events are associated with several major synchronous historical droughts across Asia, Africa and South America ${ }^{16,21}$. For instance, the strong El Niño event in 1983 caused extreme heatwaves and droughts across multiple maize-producing regions that resulted in the most extensive simultaneous crop failures in recent records ${ }^{13,17}$. Overall, $\sim 80 \%$ of historical compound droughts over tropical/subtropical belt are associated with El Niño conditions during the boreal summer ${ }^{20}$. Projected anthropogenic warming is expected to double the risk of concurrent hot and dry extremes over certain croplands and pastures ${ }^{7}$ and enhance the risk of globally synchronized shocks on temperature-sensitive crops such as Maize ${ }^{15}$, highlighting the importance of understanding the drivers of compounding stressors.

This study aims to understand future changes in the characteristics and drivers of spatially compounding droughts (hereafter compound droughts) that could result in simultaneous shocks across multiple regions, highlighting the increasing risks to a suite of climate-sensitive sectors and systems. Our analysis focuses on ten tropical and subtropical regions, defined in the Intergovernmental Panel on Climate Change (IPCC) Special Report on Managing the Risks of Extreme Events and Disasters to Advance Climate Change Adaptation (SREX), that exhibit high variability in summer precipitation and receive a large fraction of their annual precipitation during their summer season. Several of these regions exhibit similar socioeconomic and climate characteristics, including areas where rainy seasons and agricultural production are strongly 
influenced by the global monsoon systems. These regions also include important breadbaskets and vulnerable populations that depend on rainfed agriculture for their livelihood ${ }^{22,23}$. Given the importance of ENSO for hydroclimate variability over many of these regions ${ }^{13,16,24-27}$, we investigate the influence of El Niño and La Niña events on compound drought characteristics in the historical and future climates. We also quantify changes in the population and agricultural land exposure to compound droughts to understand societal implications of projected changes.

Historical and future characteristics of compound droughts. We find significant increases in the frequency, spatial extent, and average intensity of compound droughts in the late- $21^{\text {st }}$ century (2071-2100) relative to the late $20^{\text {th }}$ century (1971-2000) in the Community Earth System Model Large Ensemble simulations for the high-emissions Representative Concentration Pathway 8.5 (Figure 1). The number of regions simultaneously under drought is significantly (p-value $<0.05$ ) higher in the future relative to the historical climate (Figure 1b), contributing to a $\sim 60 \%$ increase in the probability of compound droughts (historical probability $=0.32$ and future probability $=$ 0.51 ). The fraction of drought-affected area during compound droughts is also significantly higher in the future climate, with the probability of widespread compound droughts increasing by $\sim 30 \%$ relative to the historical climate (Figure 1c). Likewise, the mean severity of compound droughts also increases (Figure 1d) along with the probability of severe compound droughts, which increases $\sim 6$-fold from 0.12 in the historical climate to 0.75 in the future climate. As a result, nearly 3 out of 4 compound droughts in the future are classified as severe (Figure 1d).

We quantify the impacts of more frequent, extensive and severe compound droughts on agricultural land (the combination of cropland and pastureland) and population by calculating changes in their exposures to compound droughts (Figure 2). These exposures exhibit distinct differences between the two climates and are sensitive to drought severity. While agriculture

101

102

103

104

105

106

107 areas exposed to moderate compound droughts in the historical climate is twice as high as in the future climate (Figure 2a), their exposure to severe compound droughts increases $\sim 10$-fold in the future climate. An average of $\sim 0.7$ million $\mathrm{km}^{2}$ of agricultural land is likely to be exposed to severe compound droughts every year in the future climate compared to $\sim 0.07$ million $\mathrm{km}^{2}$ in the historical climate (Figure 2a). Since the agricultural area does not change in the two analyses periods, the differences in exposure is largely driven by changes in the frequencies and extent of moderate and severe compound drought in the two time periods.

Increases in the severity of compound droughts in future climate is associated with changes in the characteristics of the water cycle. Specifically, several regions either exhibit a decrease in precipitation (CNA, CAM, and northern AMZ), or an increase in ET (northern CAM and ENA), both of which enhance surface drying (Figure S1c,d) and elevate the risk of compound droughts (Figure S2a). As a result, there is an increase in the likelihood of severe compound droughts exposure to agricultural lands within these regions (Figure 3a,b; Figure S2a,b). Alternatively, the decrease in agricultural exposure to moderate compound droughts over the EAS, SAS and EAF regions is due to an increase in summer precipitation in the future climate (Figure S1; Figure 3b). As a result, these regions are less likely to experience compound droughts in the future climate (Figure 3a). Although a reduction in agricultural exposure to compound droughts is projected over EAF, there is a considerable uncertainty in the response of EAF precipitation to warming ${ }^{28}$.

Differences in the distribution and growth of population in the five Shared Socioeconomic Pathways (SSPs) lead to substantially varying population exposures to compound droughts 
(Figure 2b). Future population exposure to severe (moderate) compound droughts increases (declines) under all SSPs (Figure 2b). In the historical climate, an average of $\sim 10$ million people are at risk of experiencing severe compound droughts every year, which increases to an average of $\sim 120$ million people under SSP1 and SSP5, 160 million under SSP2 and SSP4, and more than 210 million people under SSP 3 every year by the late $21^{\text {st }}$ century (Figure $2 b$ ). The exceptionally large increase in population exposure to severe compound droughts under SSP3 is primarily driven by a large increase in the frequency of severe compound droughts and in the population across all regions except SEA and EAS (Figure 3c; Figure S2c-f). Despite declines in compound droughts risk, the projected increase in population over EAF, WAF, and SAS contributes to increasing future population exposure ${ }^{29}$ (Figure 3a).

131 Physical drivers of compound droughts. ENSO is the dominant mode of natural climate 132 variability influencing compound droughts in the boreal summer season (Figure 4) ${ }^{16,20}$.

133 Historically, $\sim 68 \%$ of compound droughts are associated with significant ENSO events, of which El Niño conditions alone account for $\sim 46 \%$ of compound droughts occurrences (Figure $4 \mathrm{~b}$ ). With the projected warming, ENSO events become more frequent, including a 30\% increase in El Niño and $15 \%$ increase in La Niña conditions (Figure 4a). The more frequent occurrences of ENSO in the future warmer climate are consistent with previous studies ${ }^{30,31}$. In the future climate, $\sim 75 \%$ of compound droughts are driven by ENSO variability, and the fraction of compound droughts associated with El Niño conditions increases to $\sim 50 \%$ (Figure $4 \mathrm{~b}$ ). In total, compound droughts events associated with El Niño and La Niña conditions increase by $\sim 70 \%$, from 263 events in the historical climate to 448 in the future climate, in response to a $22 \%$ future increase (from 712 to 869 events) in the frequency of ENSO events (Figure 4a, b). The frequency of compound droughts associated with non-ENSO drivers also exhibit a moderate increase of $\sim 25 \%$ (Figure $4 \mathrm{~b}$ ). The proportional occurrence of compound droughts during El Niño and La Niña conditions is similar in both time periods (i.e., association with El Niño is $\sim 2$ (1.96) times more than La Niña in the historical (future) climate) (Figures 4b). Collectively, these characteristics of future changes not only manifest as a stronger role of ENSO in driving summer season compound droughts, but also suggest that ENSO teleconnections over the study regions remain largely stationary.

The more prominent role of El Niño in driving spatially compound droughts is due to its negative correlation with precipitation variability over most of the studied regions. El Niño conditions lead to intense and widespread drying over CAM, AMZ, WAF, EAF, EAS, southern SAS, and SEA in the historical climate (Figure S3a). In contrast, La Niña conditions lead to drying over relatively fewer studied regions, including CNA, ENA, southern WAF, and northern SEA (Figure S3c). El Niño-driven compound droughts also exhibit relatively larger mean drought extent compared to La Niña-driven compound droughts in both climates, and compared to nonENSO driven compound droughts in the historical climate (Figure 5a-c). While La Niña-driven compound droughts events exhibit higher intensity in the historical climate, more intense compound droughts are predominantly due to El Niño conditions in the late $21^{\text {st }}$ century (Figure 5c). In fact, El Niño-driven compound droughts not only have the highest mean severity in the future climate, but their extreme severity is also the highest among all the drivers (Figure $5 \mathrm{c}$ ). These changes are consistent with relatively strong future climate drying during El Niño conditions (Figure S3). The composites of Standardized Precipitation Evapotranspiration Index (SPEI) during El Niño show an expansion of the drought area over AMZ and CAM, and an intensification of dry conditions over EAF and SEA in the future climate. Some intensification of 
drying is also present during La Niña (non-ENSO) conditions over ENA, WAF and AMZ (CAM and $\mathrm{AMZ}$ ) in the future climate (Figure S3c-f).

ENSO Teleconnections. We investigate changes in the influence of ENSO over the study regions by examining its teleconnections with SPEI (Figure 6) and precipitation anomalies across the study regions (Figure S4). The magnitude and pattern of correlations between the summer ENSO index and the SPEI/precipitation is very similar in both time periods, which highlights the fact that the ENSO teleconnections over most regions remain largely stable with the exception of ENA, WAF and EAF where correlations are stronger in the future climate (Figure 6a-b,d, S4). The area with a significant correlation between SPEI and ENSO over ENA increases from $\sim 40 \%$ in the historical climate to $\sim 70 \%$ in the climate (Figure $6 \mathrm{c}$ ). Moreover, the average correlation over WAF (EAF) increases to $\sim 0.35(\sim 0.4)$ in future climate relative to $\sim 0.25(\sim 0.35)$ in the historical climate (Figure $6 \mathrm{~d}$ ). Corresponding to the relative strengthening of ENSO teleconnections, the SPEI composite shows stronger dry conditions over western EAF during El Niño conditions and over southern WAF and eastern ENA during La Niña conditions in the future climate (Figure S5). Similarly, wet conditions also exhibit strengthening over southern WAF and eastern ENA during El Niño, and over eastern EAF during La Niña conditions (Figure S4). Broadly, the nature of ENSO teleconnections remain stationary in the future climate, which highlights the importance of understanding the current ENSO-compound droughts relationship and their related physical processes ${ }^{20}$.

Discussion. Droughts are associated with a range of environmental, economic, and social impacts. Given the increasing global connectivity of socio-economic systems, understanding the historical characteristics of compound droughts and anticipating their changes in a future warmer climate is important for a broad suite of interconnected, climate-sensitive sectors ${ }^{7}$. The agricultural sector, in particular, is highly sensitive to simultaneous shocks across multiple regions because of the complex networks of food supply, demand and global trade ${ }^{6}$. The projected increase in agricultural exposure to compound droughts highlights the higher likelihood of simultaneous production shocks across multiple breadbaskets in the future period that could affect global food availability and security. Our results indicate that the North and South American regions, considered in this study, are more likely to experience compound droughts in a future warmer climate as compared to the regions in Asia and Africa, where much of the areas affected by monsoons are projected to become wetter ${ }^{32}$. The contribution of food produced within the Americas to the global food system could, therefore, be more susceptible to such climatic hazards. For instance, the United States is a major exporter of staple grains and currently exports maize (soyabean) to $>160(>90)$ countries across the globe ${ }^{11,33}$. Therefore, a modest increase in the risk of compound droughts in the future climate can lead to regional supply shortfalls that could cascade into the global market, affecting global prices and amplifying food insecurity. Additionally, our results have broader implications for the global virtual water trade network involved in the water-intensive agricultural, forestry, industrial, and mining products ${ }^{34,35}$. In last three decades, international trade of virtual water has tripled ${ }^{35}$ and is expected to increase further in response to increases in population and demand by end of 21 st century $^{36}$. Therefore, the projected increases in the frequency and severity of compound droughts could disrupt the supply-demand network of such water intensive goods and thereby, can affect their availability and prices in global market. 
In addition to impacts on such connected systems, the interplay of projected growth in

212 population and changes in compound drought characteristics will also exacerbate direct

213 population exposure to drought impacts. The largest increase in population exposure to severe

214 compound droughts is projected under SSP3, which represents a fragmented future world of resurgent nationalism, low-income growth, focus on domestic or regional issues, and high population growth in developing countries ${ }^{29}$. Persistent inequality and low economic growth under SSP3 indicate societies that are likely less resilient to severe compound droughts and consequently might experience higher socio-economic impacts. In contrast, the increase in population exposure to compound drought is lowest under SSP1. SSP1 represents a trajectory of sustainable development, lower inequality, high economic growth, higher investment in human capital and a focus on global commons ${ }^{29}$, which might be better prepared to manage the impacts of compound droughts. Irrespective of the scenario, a warming climate will amplify stresses on international agencies responsible for disaster relief by requiring the provision of humanitarian aid to a greater number of people simultaneously exposed to drought-related disasters.

Efforts to better understand and constrain the hydroclimatic impacts of ENSO variability, however, can support predictability and management of compound drought impacts in a warmer climate. Our findings suggest that the regional teleconnections during El Nino or La Nina conditions do not change substantially, with increases mainly in the intensity of compound droughts in the future climate relative to historical climate. These results imply that when ENSO events occur, they will likely affect the same geographical regions albeit with greater severity. The occurrence of nearly $75 \%$ of compound droughts with ENSO events in the future climate highlights the potential for predictability of compound droughts and their impact at lead times of up to 9 -months ${ }^{37}$. Timely predictions of compound droughts and their impacts on agricultural areas and communities can facilitate international agribusiness industries to minimize the economic losses and insurance and re-insurance industries to design effective insurance schemes to reduce losses from simultaneous disasters.

\section{References}

240 1. Zscheischler, J., Martius, O., Westra, S., Bevacqua, E. \& Raymond, C. A typology of compound weather and climate events. EGU Gen. Assem. 2020 EGU2020-8572 (2020) doi:https://doi.org/10.5194/egusphere-egu2020-8572.

2. Raymond, C. et al. extreme events. Nat. Clim. Chang. (2017) doi:10.1038/s41558-020$0790-4$.

3. AghaKouchak, A. et al. Climate Extremes and Compound Hazards in a Warming World. Annu. Rev. Earth Planet. Sci. 48, 519-548 (2020).

4. Zscheischler, J. et al. Future climate risk from compound events. Nat. Clim. Chang. 8, 469-477 (2018).

5. Leonard, M. et al. A compound event framework for understanding extreme impacts. Wiley Interdiscip. Rev. Clim. Chang. 5, 113-128 (2014).

6. Raymond, C. et al. Understanding and managing connected extreme events. Nat. Clim. Chang. 10, 611-621 (2020). 
7. Sarhadi, A., Ausín, M. C., Wiper, M. P., Touma, D. \& Diffenbaugh, N. S. Multidimensional risk in a nonstationary climate: Joint probability of increasingly severe

8. Mishra, V., Thirumalai, K., Singh, D. \& Aadhar, S. Future exacerbation of hot and dry summer monsoon extremes in India. npj Clim. Atmos. Sci. 3, 1-9 (2020).

9. Raveh-Rubin, S. \& Wernli, H. Large-scale wind and precipitation extremes in the Mediterranean: A climatological analysis for 1979-2012. Q. J. R. Meteorol. Soc. 141, 2404-2417 (2015).

10. Kornhuber, K. et al. Amplified Rossby waves enhance risk of concurrent heatwaves in major breadbasket regions. Nat. Clim. Chang. 10, 48-53 (2020).

11. Heslin, A. et al. Simulating the Cascading Effects of an Extreme Agricultural Production Shock: Global Implications of a Contemporary US Dust Bowl Event. Front. Sustain. Food Syst. 4, 1-12 (2020).

12. Anderson, W., Seager, R., Baethgen, W. \& Cane, M. Trans-Pacific ENSO teleconnections pose a correlated risk to agriculture. Agric. For. Meteorol. 262, 298-309 (2018).

13. Anderson, W. B., Seager, R., Baethgen, W., Cane, M. \& You, L. Synchronous crop

14. Gaupp, F., Hall, J., Hochrainer-stigler, S. \& Dadson, S. Changing risks of simultaneous failures and climate-forced production variability. $S c i$. $A d v$. 5, 1-10 (2019). global breadbasket failure. Nat. Clim. Chang. (2019) doi:10.1038/s41558-019-0600-z.

15. Tigchelaar, M., Battisti, D. S., Naylor, R. L. \& Ray, D. K. Future warming increases probability of globally synchronized maize production shocks. Proc. Natl. Acad. Sci. U. S. A. 115, 6644-6649 (2018).

16. Singh, D. et al. Climate and the Global Famine of 1876-78. J. Clim. 31, 9445-9467 (2018).

17. Mehrabi, Z. \& Ramankutty, N. Synchronized failure of global crop production. Nat. Ecol. Evol. 3, 780-786 (2019).

18. Mills, E. Insurance in a climate of change. Science (80-. ). 309, 1040-1044 (2005).

19. Levermann, A. Climate economics: Make supply chains climate-smart. Nature 506, 27-29 (2014).

20. Singh, J., Skinner, C. B. \& Anderson, W. B. Ampli fi ed risk of spatially compounding droughts during co-occurrences of modes of natural ocean variability. npj Clim. Atmos. Sci. 1-14 doi:10.1038/s41612-021-00161-2.

21. Mishra, V. et al. Drought and Famine in India, 1870-2016. Geophys. Res. Lett. 46, 20752083 (2019).

22. Kitoh, A. et al. Monsoons in a changing world: A regional perspective in a global context. J. Geophys. Res. Atmos. 118, 3053-3065 (2013).

23. Byers, E. et al. Global exposure and vulnerability to multi-sector development and climate change hotspots. Environ. Res. Lett. 13, (2018).

291 24. Han, T., Wang, H. \& Sun, J. Strengthened relationship between eastern ENSO and 
summer precipitation over Northeastern China. J. Clim. 30, 4497-4512 (2017).

25. Kumar, K. K., Rajagopalan, B. \& Cane, M. A. On the weakening relationship between the indian monsoon and ENSO. Science (80-. ). 284, 2156-2159 (1999).

26. Silvestri, G. E. El Niño signal variability in the precipitation over southeastern South America during austral summer. Geophys. Res. Lett. 31, 1-5 (2004).

27. Wang, B., Liu, J., Kim, H. J., Webster, P. J. \& Yim, S. Y. Recent change of the global monsoon precipitation (1979-2008). Clim. Dyn. 39, 1123-1135 (2012).

28. Rowell, D. P., Booth, B. B. B., Nicholson, S. E. \& Good, P. Reconciling past and future rainfall trends over East Africa. J. Clim. 28, 9768-9788 (2015).

29. Jones, B. \& O’Neill, B. C. Spatially explicit global population scenarios consistent with the Shared Socioeconomic Pathways. Environ. Res. Lett. 11, (2016).

30. Cai, W. et al. Increased frequency of extreme La Niña events under greenhouse warming. Nat. Clim. Chang. 5, 132-137 (2015).

31. Cai, W. et al. Increasing frequency of extreme El Niño events due to greenhouse warming. Nat. Clim. Chang. 4, 111-116 (2014).

32. Takahashi, H. G. et al. Response of the asian summer monsoon precipitation to global warming in a high-resolution global nonhydrostatic model. J. Clim. 33, 8147-8164 (2020).

33. FAOSTAT. Detailed Trade Matrix. Food and Agriculture Organization of the United Nations. Available online at: http://www.fao.org/faostat/en/\#data/ TM (accessed March 1, 2021). (2020).

34. Dalin, C., Wada, Y., Kastner, T. \& Puma, M. J. Groundwater depletion embedded in international food trade. Nature 543, 700-704 (2017).

35. D'Odorico, P. et al. Global virtual water trade and the hydrological cycle: Patterns, drivers, and socio-environmental impacts. Environ. Res. Lett. 14, (2019).

36. Graham, N. T. et al. Future changes in the trading of virtual water. Nat. Commun. 11, 1-7 (2020).

37. Barnston, A. G., Tippett, M. K., L'Heureux, M. L., Li, S. \& Dewitt, D. G. Skill of realtime seasonal ENSO model predictions during 2002-11: Is our capability increasing? Bull. Am. Meteorol. Soc. 93, 631-651 (2012).

\section{Methods}

Datasets. We use the 40-member Community Earth System Model Version-1 (CESM1) Large Ensemble Simulations (LENS) to examine the drivers of historical (1971-2000) compounding droughts and their projected changes (2071-2100) under the RCP8.5 scenario ${ }^{38}$. Each ensemble member of the CESM-LENS differs only in its initial atmospheric conditions and has identical external forcing, thereby providing an opportunity to investigate the influence of internal variability under different climate conditions. CESM demonstrates high skill in reproducing the observed global precipitation patterns, ENSO characteristics (e.g., intensity, frequency and related global teleconnections) ${ }^{30,31,39}$.. 
We use observed monthly precipitation data for 1981-2019 from the Climate Hazards Group Infrared Precipitation with Stations (CHIRPS) version $2^{40}$ to estimate the Shannon Entropy index ${ }^{41}$, which is used to identify the regions of high variability in the summer precipitation. CHIRPS combines satellite-based precipitation estimates with in-situ observations and models of terrain-based precipitation to provide spatially fine and continuous data ${ }^{40}$. For the calculation of changes in population and agricultural land exposures, historical (for the year 2000) and projected future population (for the year 2100) at 1-km spatial resolution ${ }^{42}<$

\section{https://sedac.ciesin.columbia.edu/data/set/popdynamics-1-km-downscaled-pop-base-year-} projection-ssp-2000-2100-rev01>, and crop and pastureland fraction (based on the year 2000) $<$ https://sedac.ciesin.columbia.edu/data/set/aglands-pastures-2000 $>$ at $10-\mathrm{km}$ spatial resolution ${ }^{43}$ are obtained from the NASA Socioeconomic Data and Applications Center. We consider the population projections from all five Shared Socioeconomic Pathways (SSPs) to quantify the uncertainty in population exposure to compounding droughts under projected future warming.

Selection of Regions. We quantify compound droughts across 10 SREX regions: Amazon (AMZ), Central America (CAM), Central North America (CNA), East Africa (EAF), East Asia (EAS), East North America (ENA), South Asia (SAS), Southeast Asia (SEA), Tibetan Plateau (TIB), and West Africa (WAF). We consider these regions for the following reasons: (1) many of these regions are connected by the global summer monsoon systems and influenced by similar large-scale modes of variability 27 , (2) these receive the largest fraction of annual precipitation during the summer season (June - September; JJAS) ${ }^{22,27}$ and exhibit strong variability in summer precipitation, and (3) these include several major breadbaskets and populations vulnerable to climate variability and change ${ }^{23}$.

To identify the sub-regions that exhibit high variability in summer precipitation, we estimate the observed Shannon Entropy Index ${ }^{41}$ using monthly summer precipitation from the CHIRPS dataset. We only consider those regions that show high variability (entropy $>4.86$; median entropy values across the areas studied) in the monthly summer precipitation over at least $30 \%$ of their total area (Figure 1a). The Shannon Entropy $H$ is estimated using the following equation ${ }^{44}$,

where, $p$ is the probability of each $i^{\text {th }}$ value of the time series. The areas within each region that satisfy the Shannon entropy criterion compare well between observations (CHIRPS) and simulations (CESM) (Figures 1a, S6). The only exception is over AMZ where the extent of simulated area with high variability is relatively smaller than observed (Figure S6). Furthermore, CESM exhibits skills in simulating the compound droughts characteristics across these regions that have been described in Singh et $a l^{20}$.

Drought Characteristics. We use Standardized Precipitation Evapotranspiration Index (SPEI) to define drought ${ }^{45,46}$. SPEI is estimated using a simple climatic water balance, i.e., the difference between the accumulated summer season precipitation and evapotranspiration (ET) ${ }^{45}$. We compute ET as the sum of ground and canopy evaporation and transpiration for the present and future climates from CESM-LENS following the approach provided by Mankin et al ${ }^{47}$. To 
construct SPEI, we follow a procedure similar to the Standardized Precipitation Index calculations proposed by McKee et a ${ }^{48}$. We use a log-Logistic distribution to estimate the probability distribution of P-ET instead of the Gamma distribution ${ }^{45}$ that is used for SPI ${ }^{49}$. The gamma distribution requires a variable with non-negative values, which makes it inappropriate for SPEI estimation because the P-ET may yield negative values. Hence, we estimate the probability of P-ET based on the widely used two-parameter Log-logistic distribution and then transform it to a standard normal distribution to make it comparable across space and time ${ }^{45,46}$. Future (2071-2100) SPEI calculations use historical (1971-2000) climate characteristics to characterize changes in compound droughts relative to the historical climate.

We use the threshold of $-1 \sigma$ of the historical SPEI to classify a grid cell experiencing drought $(<-$ $1 \sigma)$ in the historical and future climates. We define an individual drought over a region if the fractional area experiencing drought conditions $(\mathrm{SPEI}<-1 \sigma)$ exceeds the $80^{\text {th }}$ percentile of the historical long-term average drought area. A compound droughts event is identified if at least three of the ten SREX regions concurrently experience drought. Compound drought area is defined as the fraction of the total area across the regions involved in compound droughts events. Similarly, the compound droughts intensity is computed as average SPEI over drought-affected areas across those regions. A compound drought event is classified as widespread when the drought-affected area exceeds the $90^{\text {th }}$ percentile of the historical long-term average area affected by compound droughts (i.e. $41 \%$ ). Furthermore, these events are classified as severe (moderate) when average SPEI across all drought-affected areas is below (above) the 10th percentile ( 1.65) of the historical long-term average SPEI over drought-affected areas during compound droughts.

Crop, pasture lands and population exposure. There is a mismatch between the horizontal grid spacing of climate data and cropland, pastureland and population datasets. Moreover, the rate of population growth varies across space and depends on several local and global spatial interactions ${ }^{29}$. Therefore, it is not appropriate to use interpolation methods to upscale the population data to match $\sim 1^{\circ}$ CESM grid cells. Therefore, instead of remapping, we aggregate the population across the grid cells (at $1 \mathrm{~km}$ spatial resolution) that fall inside the $\sim 1^{\circ} \mathrm{CESM}$ grid cells to calculate population exposure. We follow same procedure for crop and pasture lands. Given the importance of cropland for food cultivation and pastureland for animals grazing, we quantify the exposure of these land types to compound droughts. Cropland, pastureland and population exposures are calculated as follows:

$$
\text { Cropland and pastureland exposure: } \frac{1}{N} \sum_{i=1}^{n} a_{i}
$$

where, $N$ is number of years, $i$ indicates years with compound droughts events, $a$ indicates the total drought affected cropland or pastureland across the regions involved in the compound droughts. Cropland and pastureland is based on the year 2000 and is fixed for both present and future climates.

$$
\text { Population exposure: } \frac{1}{\mathrm{~N}} \sum_{\mathrm{i}=1}^{\mathrm{n}} \mathrm{p}_{\mathrm{i}}
$$


Where, $N$ is number of years, $i$ indicates years with compound drought, $p$ indicates the number of people experiencing drought across the regions involved in the compound droughts. We consider historical population based on year 2000 and projected future population based on year 2100 under all five SSPs.

Large-scale Modes of Variability. We define the ENSO index using the average summer (June to September; JJAS) sea surface temperatures anomalies (SSTA) over the Niño3.4 region (5S$5 \mathrm{~N}, 170 \mathrm{~W}-120 \mathrm{~W})^{50}$. We remove the forced climate change component from each member of the large ensemble by subtracting the time-varying mean of all ensemble members, as follows:

$$
S S T A_{i, j}=S S T_{i, j}-\left(\frac{1}{40} \sum_{j=1}^{j=40} S S T_{j}\right)_{i}
$$
defined as exceedances of $\pm 0.5 \sigma$, where the standard deviation $(\sigma)$ is estimated using the historical ENSO index values $(1971-2000)^{20}$.

431 Statistical Significance of the changes in compound droughts. We employ the non-parametric permutation test to assess the statistical significance of the differences in mean compound droughts characteristics in the historical and future climates ${ }^{51}$. We first quantify the test statistic (i.e. difference in the means of the distributions of compound droughts characteristics) from the two original historical and future distributions and then estimate an empirical distribution of the test statistic by randomly permuting the samples from the two distributions and re-estimating the test statistic from the resampled distributions, 10,000 times. If the original test statistic is higher (lower) than the $95^{\text {th }}\left(5^{\text {th }}\right)$ percentile of the empirical distribution, we consider the mean of compound droughts characteristics between historical and future climates to be significantly different at the 5 percent significance level.

\section{Data availability}

442 All datasets used in the manuscript are publicly available and their sources are provided in the "Methods" section.

\section{Code availability}

445 The scripts developed to analyze these datasets can be made available on request from the corresponding author.

\section{References}

38. Kay, J. E. et al. The community earth system model (CESM) large ensemble project : A community resource for studying climate change in the presence of internal climate variability. Bull. Am. Meteorol. Soc. 96, 1333-1349 (2015).

39. Fasullo, J. T., Otto-Bliesner, B. L. \& Stevenson, S. ENSO's Changing Influence on Temperature, Precipitation, and Wildfire in a Warming Climate. Geophys. Res. Lett. 45, 
9216-9225 (2018).

40. Funk, C. et al. The climate hazards infrared precipitation with stations - A new environmental record for monitoring extremes. Sci. Data 2, 1-21 (2015).

41. Shannon, C. . A mathematical theory of communication. Bell. Syst. Tech. J. 27, 623-656 (1948).

42. Gao, J. Global 1-km Downscaled Population Base Year and Projection Grids Based on the Appl. Cent. (2020).

43. Ramankutty, N., Evan, A. T., Monfreda, C. \& Foley, J. A. Global Agricultural Lands: Croplands, 2000. Palisades, NY NASA Socioecon. Data Appl. Cent. (2010).

44. Mishra, A. K., Özger, M. \& Singh, V. P. An entropy-based investigation into the variability of precipitation. J. Hydrol. 370, 139-154 (2009).

45. Vicente-Serrano, S. M., Beguería, S. \& López-Moreno, J. I. A multiscalar drought index sensitive to global warming: The standardized precipitation evapotranspiration index. $J$. Clim. 23, 1696-1718 (2010).

46. Beguería, S., Vicente-Serrano, S. M., Reig, F. \& Latorre, B. Standardized precipitation evapotranspiration index (SPEI) revisited: Parameter fitting, evapotranspiration models, tools, datasets and drought monitoring. Int. J. Climatol. 34, 3001-3023 (2014).

47. Mankin, J. S. et al. Influence of internal variability on population exposure to hydroclimatic changes. Environ. Res. Lett. 12, (2017).

48. McKee, B. T., Nolan, D. J. \& John, K. THE RELATIONSHIP OF DROUGHT FREQUENCY AND DURATION TO TIME SCALES. Eighth Conf. Appl. Climatol. 179-184 (1993) doi:10.1002/jso.23002.

49. Mishra, A. K. \& Singh, V. P. A review of drought concepts. J. Hydrol. 391, 202-216 (2010).

50. Rayner, N. A. et al. Global analyses of sea surface temperature, sea ice, and night marine air temperature since the late nineteenth century. J. Geophys. Res. D Atmos. 108, (2003).

51. Good, P. I. Permutation tests: A practical guide to resampling methods for testing hypotheses. (Springer-Verlag, 1994).

\section{Acknowledgements}

We would like to thank the National Center for Atmospheric Research (NCAR) and Climate Hazards Center UC Santa Barbara for archiving and enabling public access to their data. We thank Washington State University for the startup funding that has supported J.S. and D.S. W.B.A. acknowledges funding from Earth Institute Postdoctoral Fellowship. M.A. was supported by the National Climate-Computing Research Center, which is located within the National Center for Computational Sciences at the ORNL and supported under a Strategic Partnership Project, 2316-T849-08, between DOE and NOAA. This manuscript has been coauthored by employees of Oak Ridge National Laboratory, managed by UT Battelle, LLC, under contract DE-AC05-00OR22725 with the U.S. Department of Energy (DOE). The publisher, by accepting the article for publication, acknowledges that the United States Government retains a non-exclusive, paid-up, irrevocable, world-wide license to publish or reproduce the published 
495 form of this manuscript, or allow others to do so, for United States Government purposes. The 496 Department of Energy will provide public access to these results of federally sponsored research 497 in accordance with the DOE Public Access Plan (http://energy.gov/downloads/doe-public498 access-plan).

\section{Author Contributions}

502 All authors contributed to the design of the study. J.S. collected the data and performed the 503 analyses. All authors were involved in discussions of the results. J.S. and D.S. wrote the 504 manuscript with feedback from all authors.

\section{Competing Interests}

507 The authors declare no competing interests. 

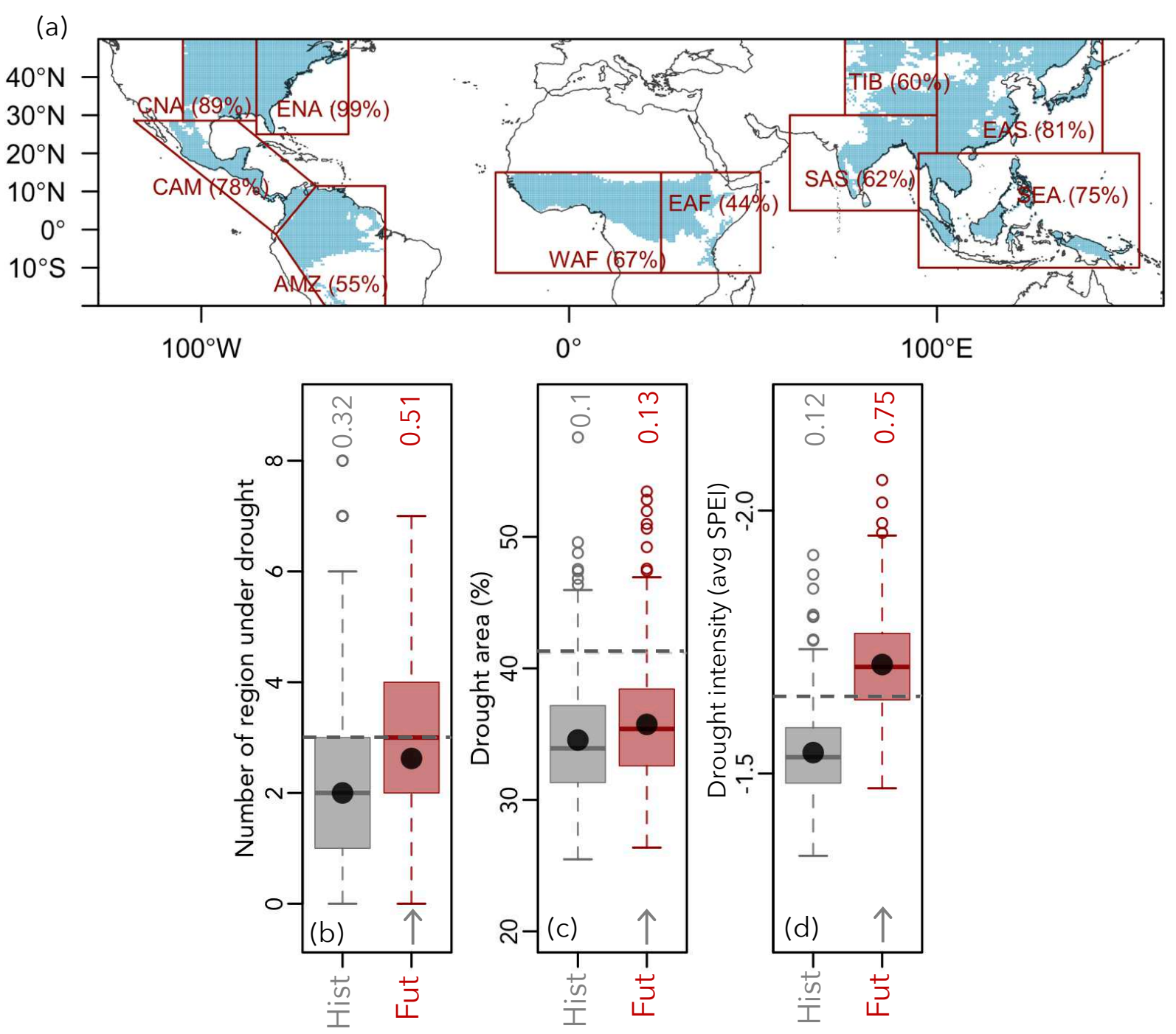

Figure 1. Historical and future characteristics of compound droughts. (a) Map showing the 10 SREX regions (red line) considered in this study. Red text indicates the fraction of each SREX region with high entropy values [entropy $>4.86$, which is the median entropy value across 10 SREX regions] (teal color) estimated from observed CHIRPS precipitation data (1981-2018) at $0.25^{0}$ resolution. (b) The distribution of the number of regions under drought in historical (grey box) and future (red box) climate. Figures (c) and (d) show the distribution of drought area and intensity associated with compound droughts. Horizontal grey dashed lines indicate the thresholds used to define (b) compound (i.e., $\geq 3$ regions under drought, gray line) drought, (c) widespread (i.e., events with $>90$ th percentile of total area $(\sim 41 \%)$ across all 10 regions concurrently affected by drought), and (d) severe (i.e., average SPI across all drought affected areas $<10$ th percentile $(\sim-1.65)$, gray line) compound drought. Text above the boxplots in panel (b) indicates the probability of compound droughts, (c) indicates the probability of experiencing widespread compound droughts and (d) indicates the probability of experiencing severe 
compound droughts. Gray arrows at the bottom of the panels indicate significant differences (at $5 \%$ significance level) in the future distribution of drought regions, drought area and intensity relative to the historical climate. Black dots show the mean of the distribution in each boxplot.

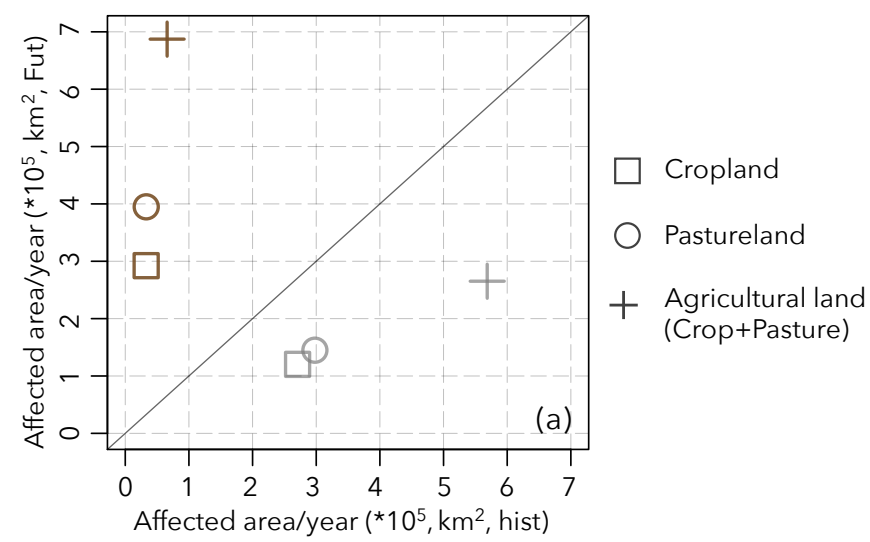

Moderate compound drought

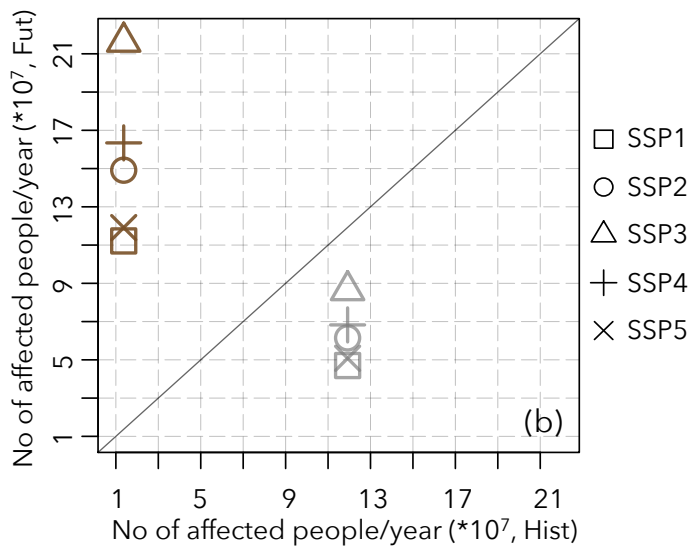

Severe compound drought

\section{Figure 2. Crop, pasture lands, and population exposure to compound droughts. (a)}

Agricultural area and (b) population exposure across the regions under compound droughts. Xand $\mathrm{Y}$ - axes indicate the average cropland/pastureland/agricultural land (combined cropland and pastureland) area and population per year exposed to compound droughts in the historical and future climate, respectively. A 45-degree solid line is used to compare exposure between historical and future climates at 1:1 in each panel.

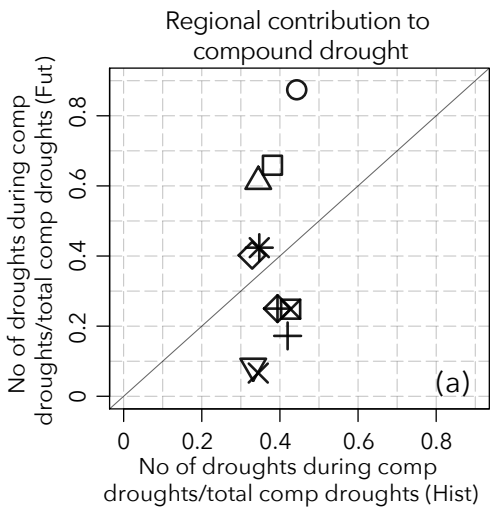

Figure 3. Contribution of regions to compound droughts and to agricultural area and population exposure to compound drought. (a) X-and $\mathrm{Y}$ - axes indicate the fraction of instances in which a particular region experiences drought during compound droughts in the historical and future climates, respectively. (b) Average agricultural land (total cropland and pastureland) (in \%) exposure to compound droughts in historical and future climates. (c) Average number of people exposed to compound droughts in historical and future climates under SSP3. 

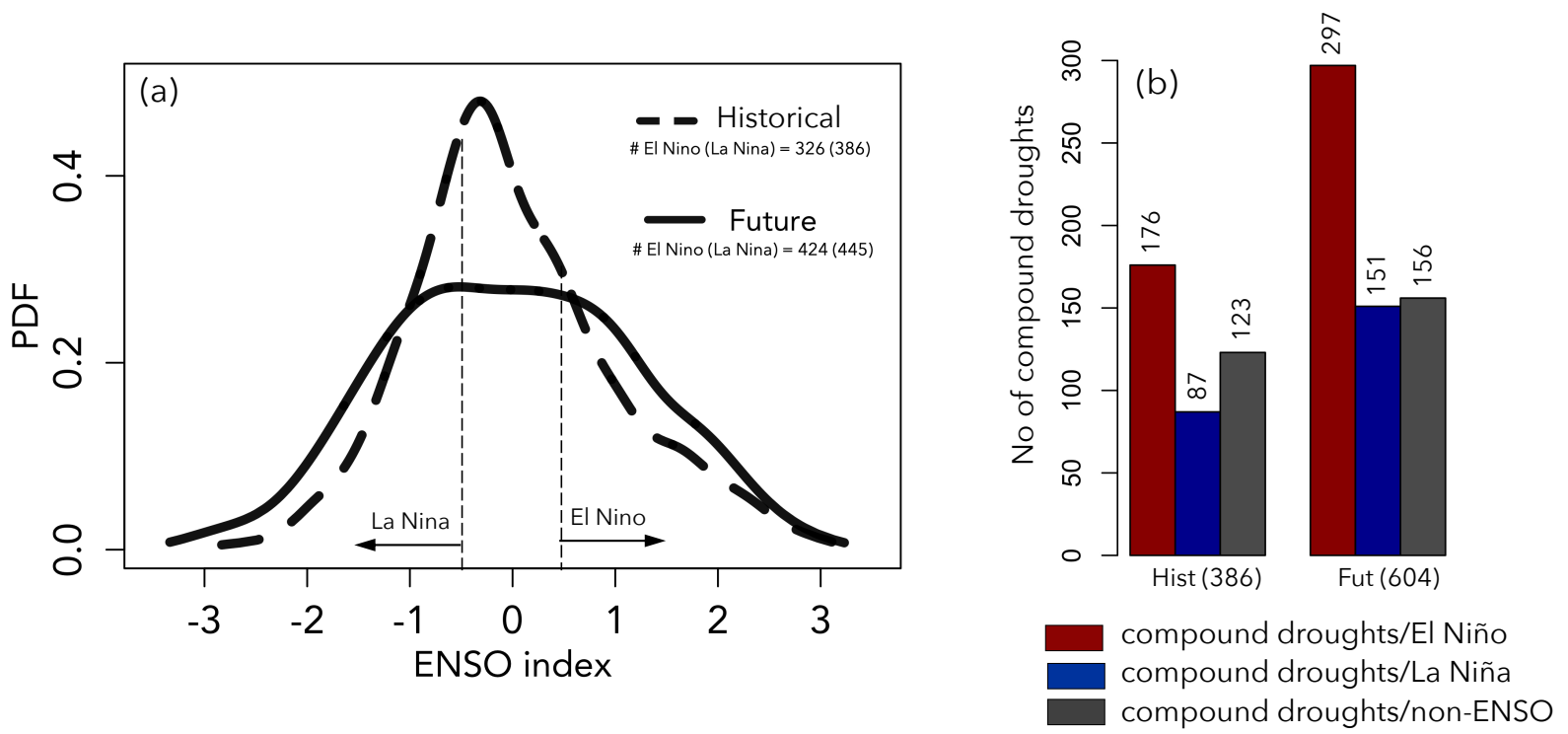

Figure 4. Changes in the frequency of ENSO events and compound droughts in future climate. (a) The probability distribution function (PDF) of the ENSO index. The text in the inset indicates the number of El Niño (ENSO $>0.5 \mathrm{SD}$ ) and La Niña $(\mathrm{ENSO}<-0.5 \mathrm{SD})$ events in the historical and future climate. (b) The count of compound droughts associated with El Niño events, La Niña events and non-ENSO drivers. The text on the x-axis indicates the total number of compound droughts in the historical and future climates. The text on top of each bar indicates the number of compound droughts that occur with the various physical drivers. 


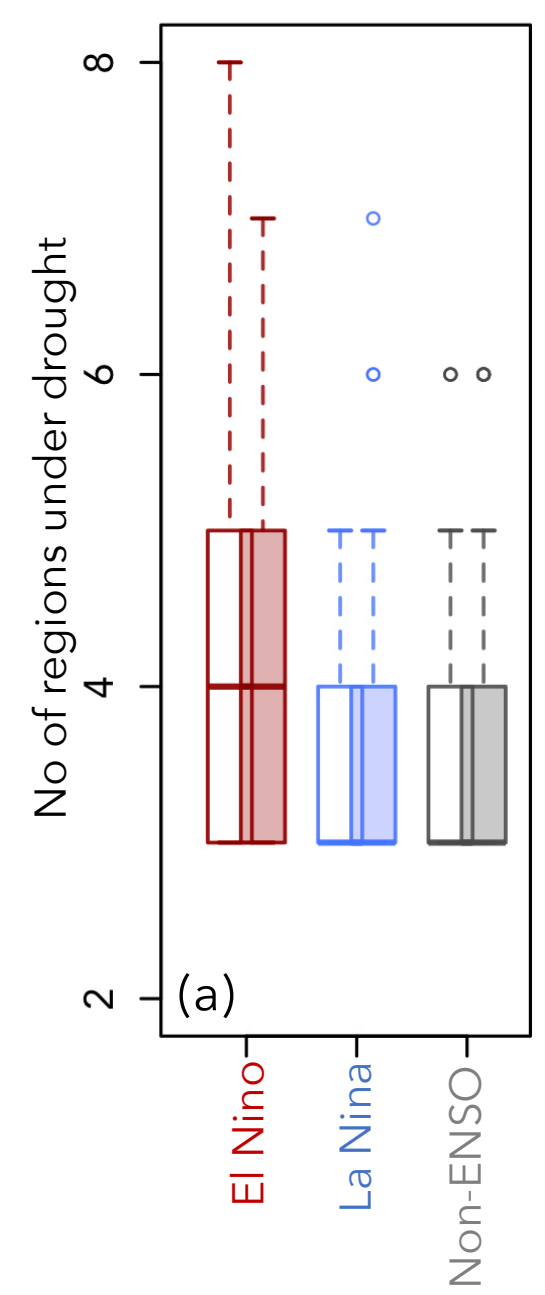

587

588

589

590

591

592
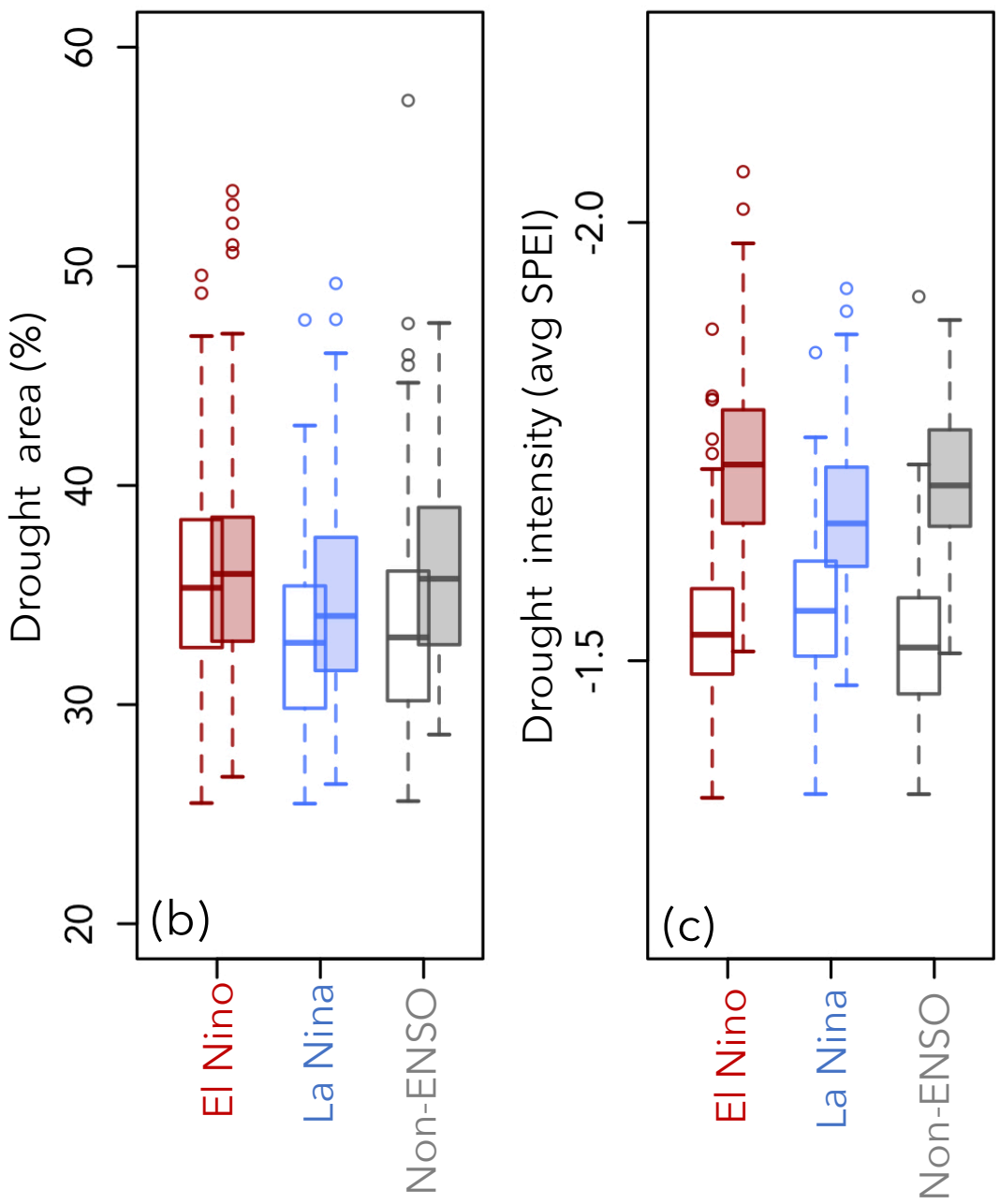

Future
Figure 5. Influence of ENSO and non-ENSO drivers on compound drought characteristics.

The distribution of (a) number of regions under drought, (b) drought area, and (c) drought intensity associated with compound droughts related to various physical drivers noted below each boxplot. 

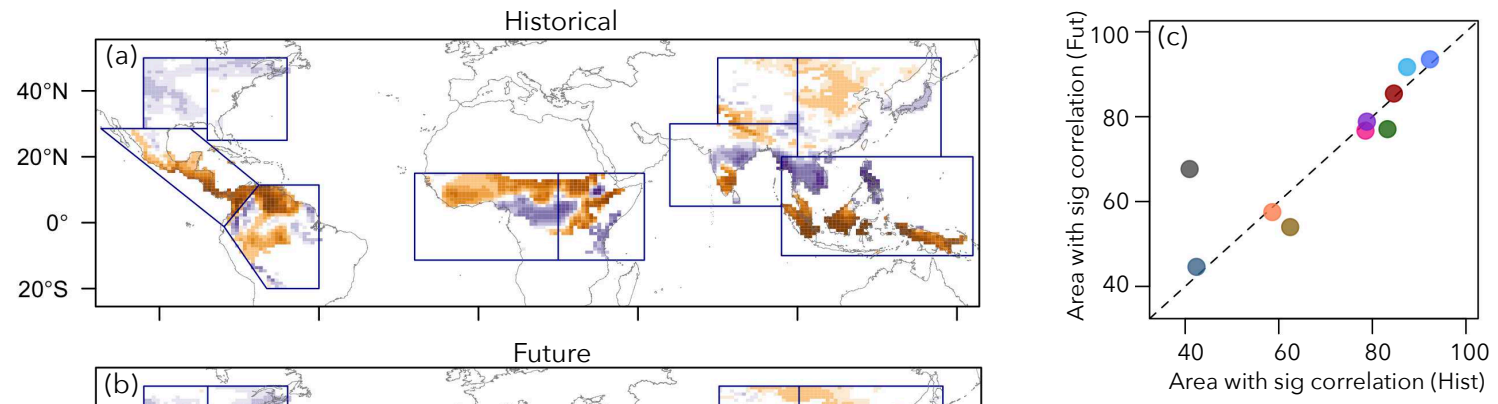

Future

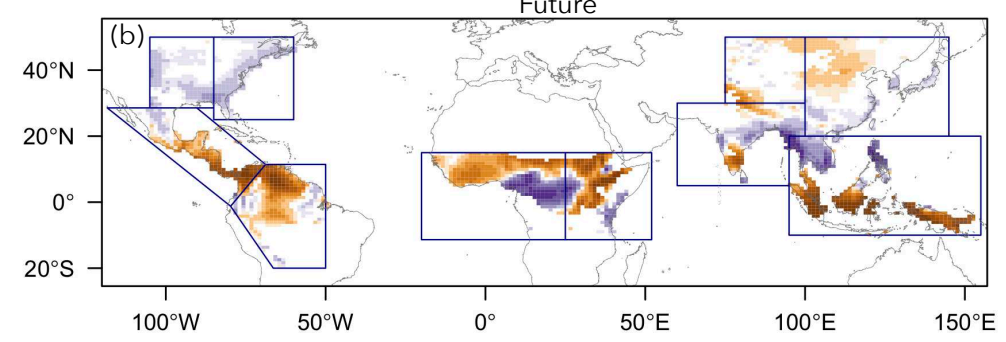

Correlation coefficient

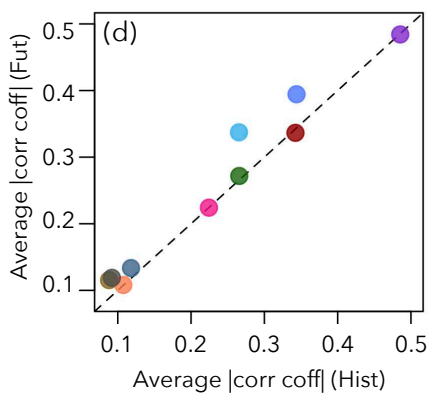

- EAS

- ENA

- SAS

- SEA

- TIB

- WAF

Figure 6. Changes in the ENSO teleconnections with SPEI over land in future climate.

Correlation between ENSO and SPEI in the (a) historical and (b) future climate. (c) Changes in the area with significant (at 5\% significance level) correlation between ENSO and SPEI across all regions in the future relative to the historical climate. (d) the changes in the strength of correlation (average absolute correlation coefficient) between ENSO and SPEI across all regions in the future relative to historical climate. 


\section{Figures}
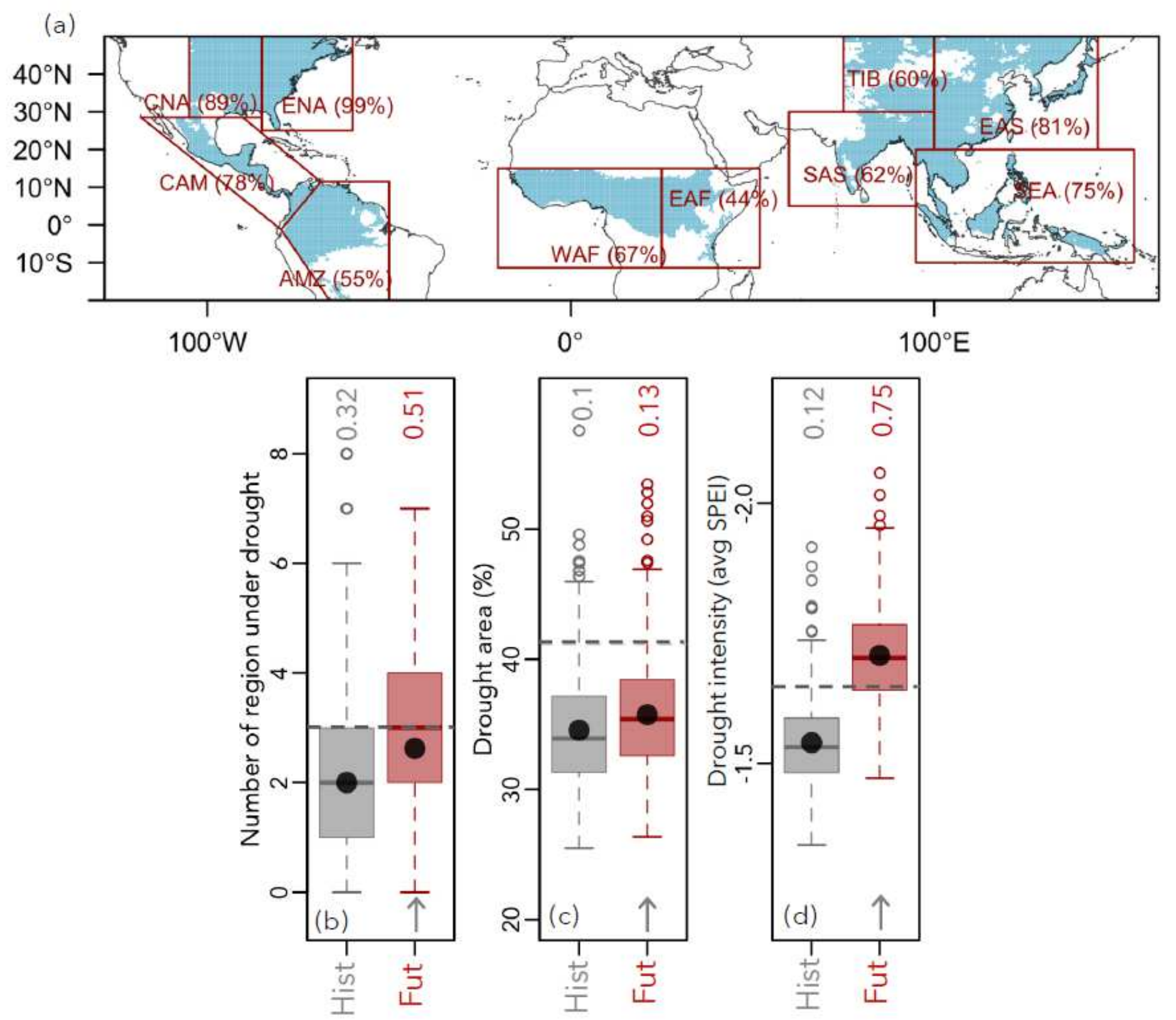

\section{Figure 1}

Historical and future characteristics of compound droughts. (a) Map showing the 10 SREX regions (red line) considered in this study. Red text indicates the fraction of each SREX region with high entropy values [entropy $>4.86$, which is the median entropy value across 10 SREX regions] (teal color) estimated from observed CHIRPS precipitation data (1981-2018) at 0.250 resolution. (b) The distribution of the number of regions under drought in historical (grey box) and future (red box) climate. Figures (c) and (d) show the distribution of drought area and intensity associated with compound droughts. Horizontal grey dashed lines indicate the thresholds used to define (b) compound (i.e., $\geq 3$ regions under drought, gray line) drought, (c) widespread (i.e., events with >90th percentile of total area ( 41\%) across all 10 regions 
concurrently affected by drought), and (d) severe (i.e., average SPI across all drought affected areas < 10th percentile ( -1.65), gray line) compound drought. Text above the boxplots in panel (b) indicates the probability of compound droughts, (c) indicates the probability of experiencing widespread compound droughts and (d) indicates the probability of experiencing severe compound droughts. Gray arrows at the bottom of the panels indicate significant differences (at $5 \%$ significance level) in the future distribution of drought regions, drought area and intensity relative to the historical climate. Black dots show the mean of the distribution in each boxplot. Note: The designations employed and the presentation of the material on this map do not imply the expression of any opinion whatsoever on the part of Research Square concerning the legal status of any country, territory, city or area or of its authorities, or concerning the delimitation of its frontiers or boundaries. This map has been provided by the authors.

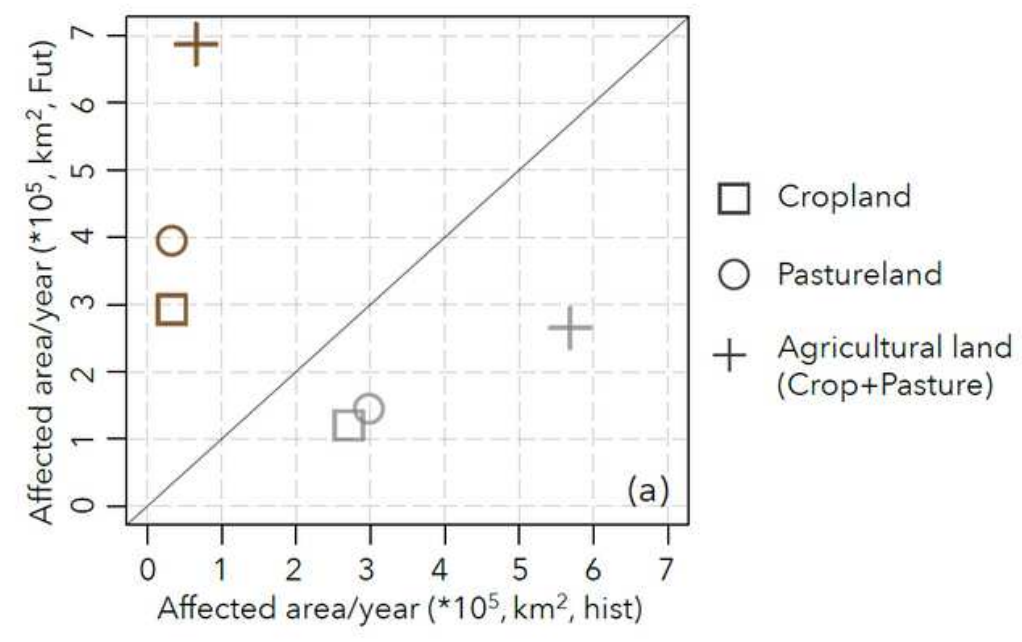

Moderate compound drought

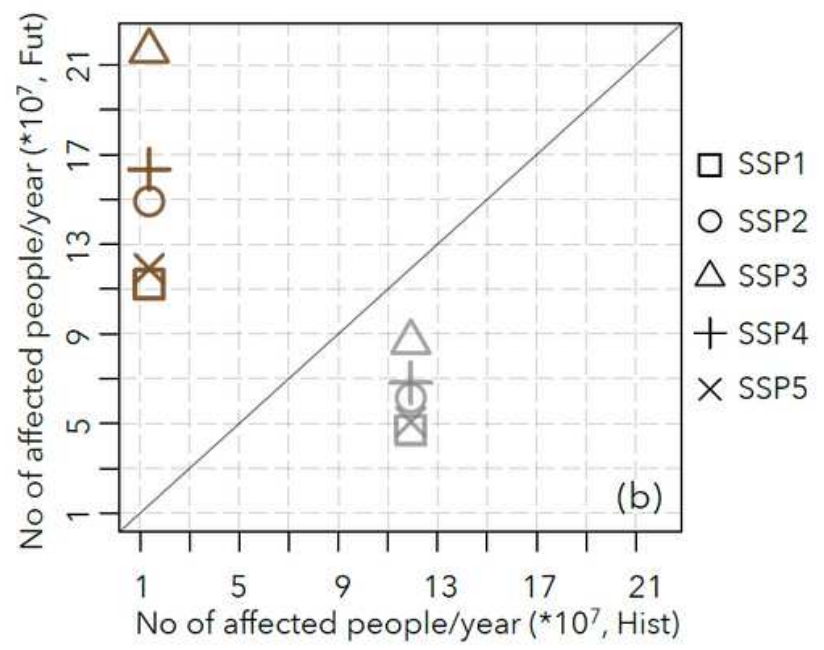

Severe compound drought

\section{Figure 2}

Crop, pasture lands, and population exposure to compound droughts. (a) Agricultural area and (b) population exposure across the regions under compound droughts. $\mathrm{X}$ and $\mathrm{Y}$ - axes indicate the average cropland/pastureland/agricultural land (combined cropland and pastureland) area and population per year exposed to compound droughts in the historical and future climate, respectively. A 45-degree solid line is used to compare exposure between historical and future climates at 1:1 in each panel. 

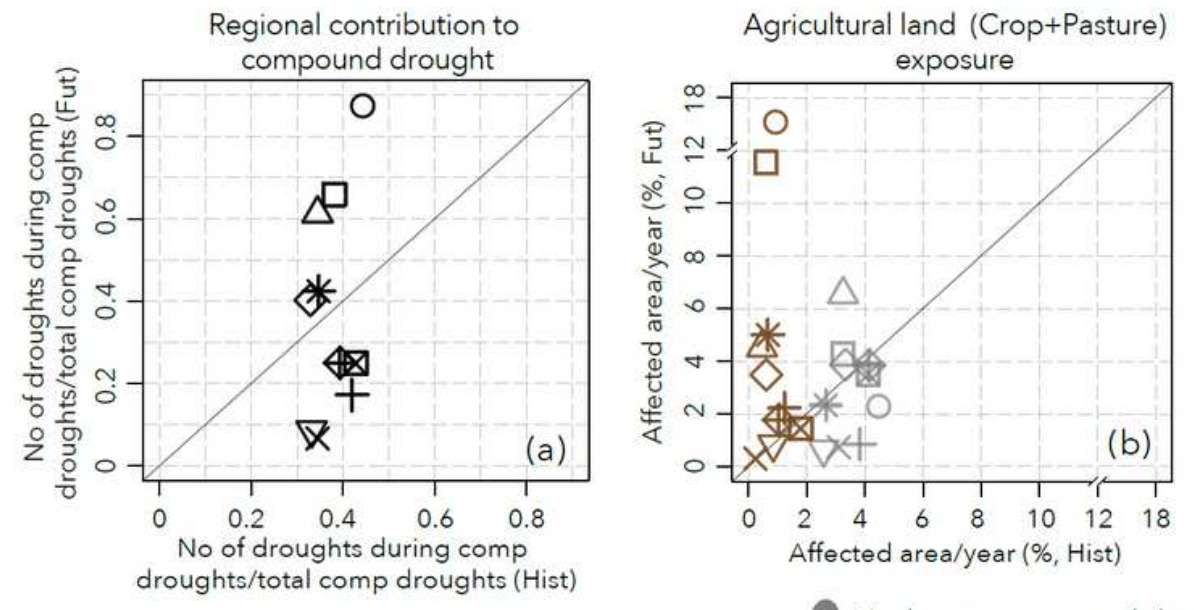

Moderate compound drought

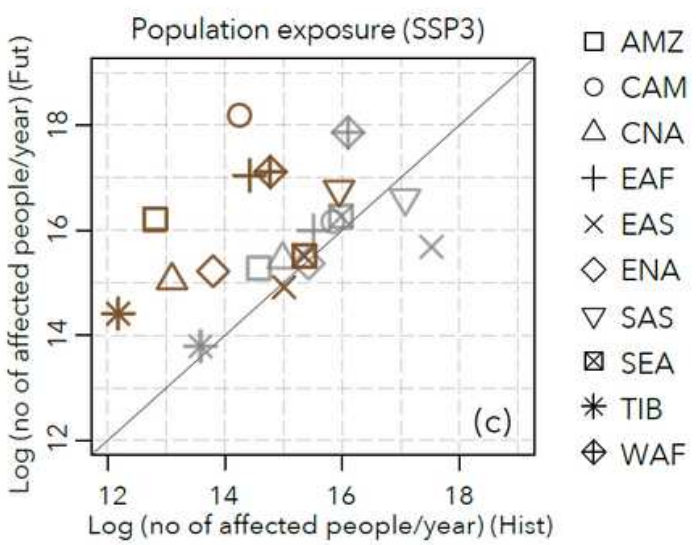

Severe compound drought

\section{Figure 3}

Contribution of regions to compound droughts and to agricultural area and population exposure to compound drought. (a) X-and $\mathrm{Y}$ - axes indicate the fraction of instances in which a particular region experiences drought during compound droughts in the historical and future climates, respectively. (b) Average agricultural land (total cropland and pastureland) (in \%) exposure to compound droughts in historical and future climates. (c) Average number of people exposed to compound droughts in historical and future climates under SSP3.
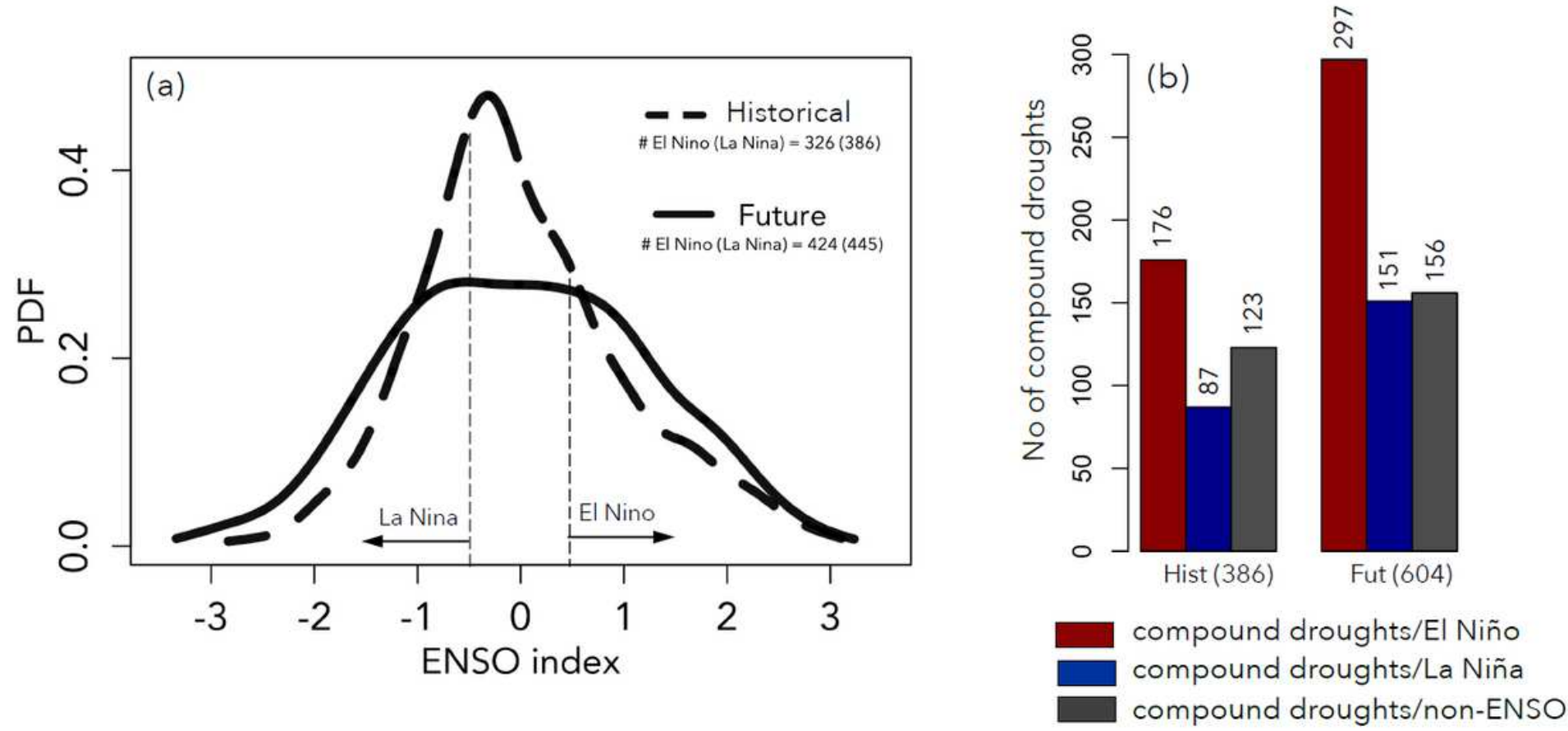

Figure 4

Changes in the frequency of ENSO events and compound droughts in future climate. (a) The probability distribution function (PDF) of the ENSO index. The text in the inset indicates the number of El Niño (ENSO $>0.5 S D$ ) and La Niña (ENSO <-0.5SD) events in the historical and future climate. (b) The count of 
compound droughts associated with El Niño events, La Niña events and non-ENSO drivers. The text on the $\mathrm{x}$-axis indicates the total number of compound droughts in the historical and future climates. The text on top of each bar indicates the number of compound droughts that occur with the various physical drivers.
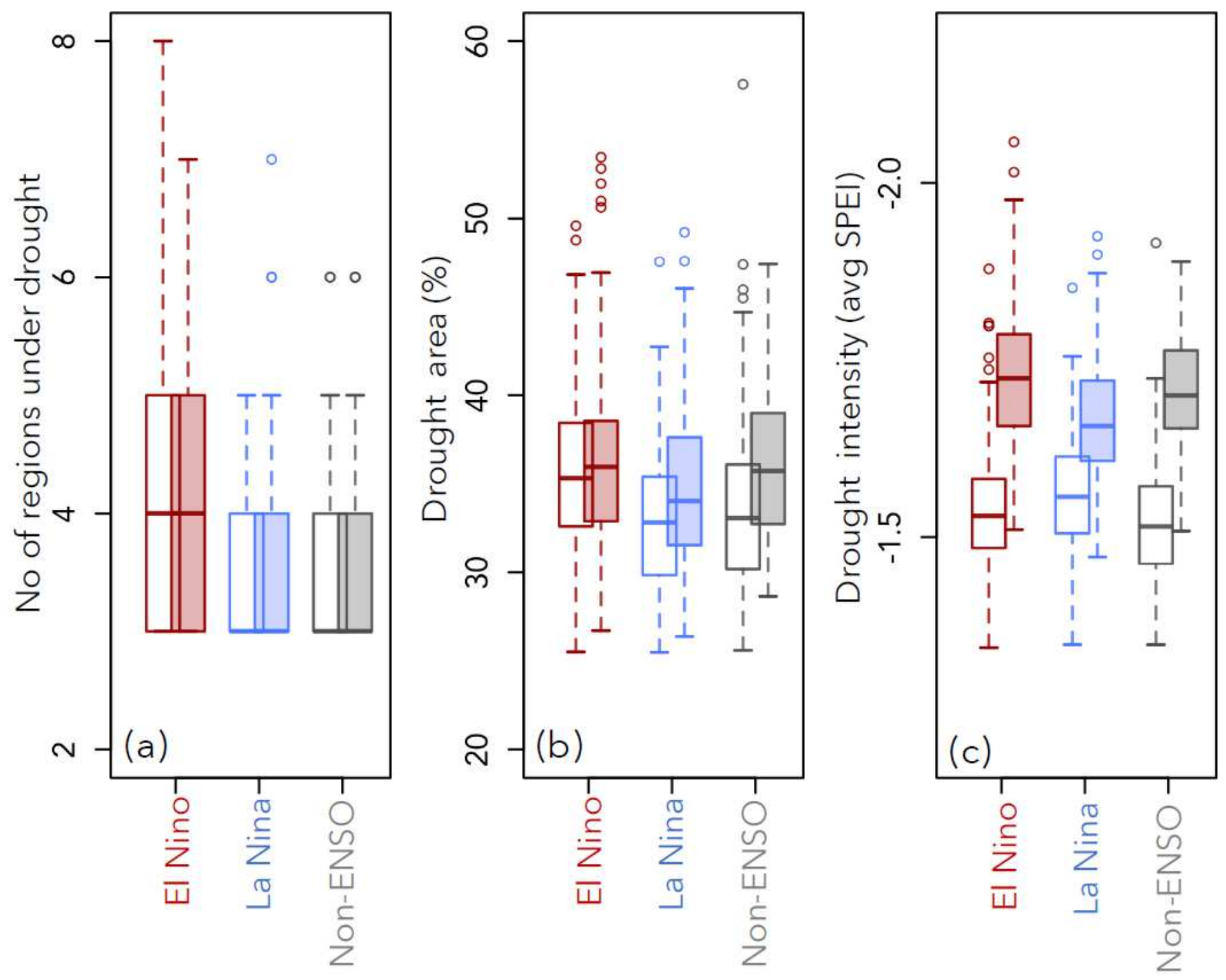

Historical

Future

Figure 5

Influence of ENSO and non-ENSO drivers on compound drought characteristics. The distribution of (a) number of regions under drought, (b) drought area, and (c) drought intensity associated with compound droughts related to various physical drivers noted below each boxplot. 


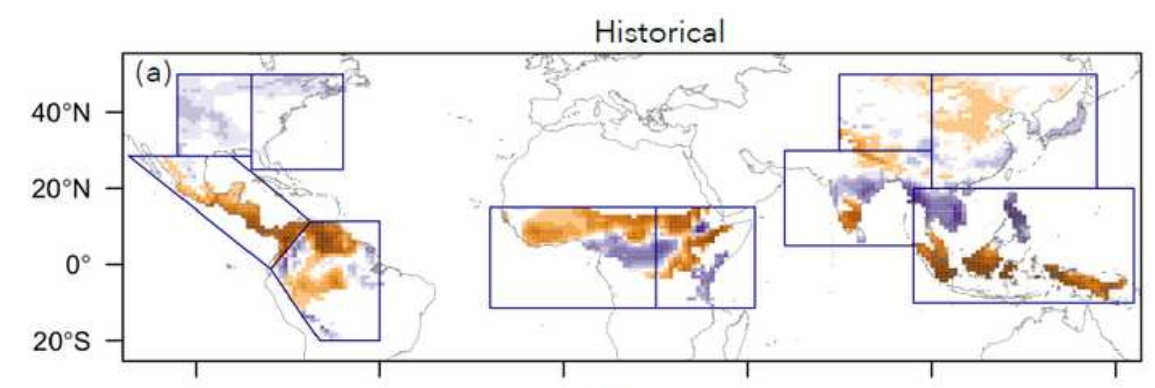

Future

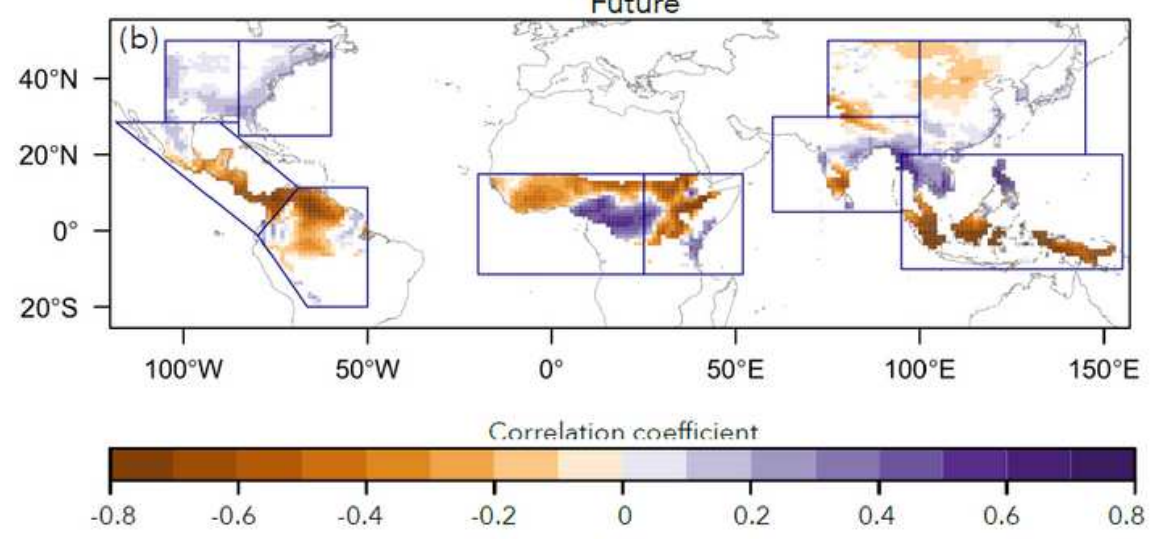

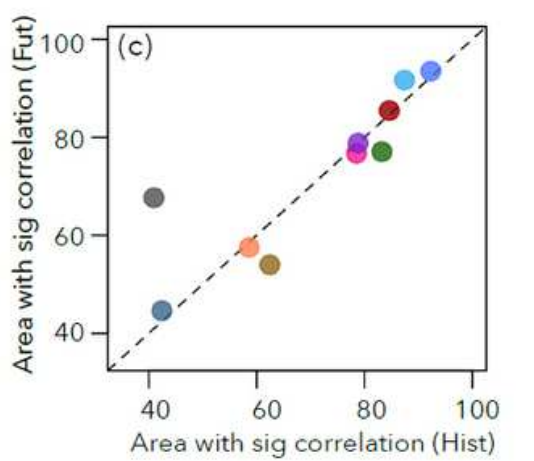

- AMZ

- CAM

- CNA

- EAF

- EAS

- ENA

- SAS

- SEA

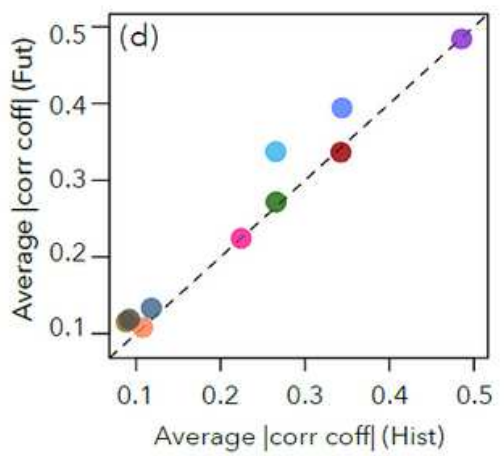

Figure 6

Changes in the ENSO teleconnections with SPEI over land in future climate. Correlation between ENSO and SPEI in the (a) historical and (b) future climate. (c) Changes in the area with significant (at $5 \%$ significance level) correlation between ENSO and SPEI across all regions in the future relative to the historical climate. (d) the changes in the strength of correlation (average absolute correlation coefficient) between ENSO and SPEI across all regions in the future relative to historical climate. Note: The designations employed and the presentation of the material on this map do not imply the expression of any opinion whatsoever on the part of Research Square concerning the legal status of any country, territory, city or area or of its authorities, or concerning the delimitation of its frontiers or boundaries. This map has been provided by the authors.

\section{Supplementary Files}

This is a list of supplementary files associated with this preprint. Click to download.

- SupplementaryfiguresFinal.pdf 